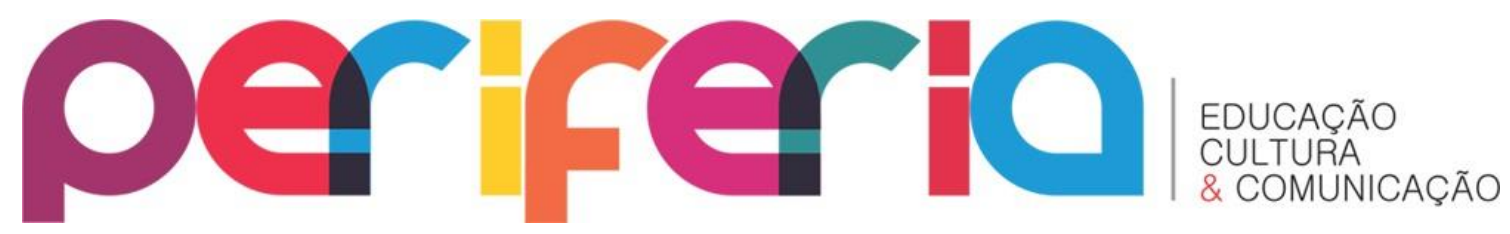

\title{
FORMAÇÃO CONTINUADA DA SECRETARIA MUNICIPAL DE EDUCAÇÃO DE BELÉM: O PROJETO EXPERTISE EM ALFABETIZAÇÃO SOB O “OLHAR” DOS PROFESSORES
}

\author{
Mary Jose Almeida Pereira ${ }^{1}$ \\ Universidade Federal do Pará \\ Ney Cristina Monteiro de Oliveira ${ }^{2}$ \\ Universidade Federal do Pará
}

\section{RESUMO}

O artigo teve como objetivo analisar o Projeto Expertise em Alfabetização, que compõe uma das ações da política de formação continuada da secretaria municipal de Educação de Belém. De forma, mais específica analisamos a relevância desse projeto de formação para o trabalho dos professores alfabetizadores, percebendo a lógica de resultados de desempenho e as exigências do cumprimento de metas. Como base metodológica utilizamos a abordagem de pesquisa qualitativa, e como instrumentos de coletas de dados a entrevista semiestruturada. Os dados foram organizados em categorias interpretativas e com base na análise de discurso. Constatamos, nas falas dos professores que a formação do Projeto Expertise tem atribuído responsabilidades, para além das condições de trabalho disponibilizadas pela secretaria de educação.

Palavras-chave: formação continuada; professores; alfabetização.

\section{CONTINUING EDUCATION OF THE SECRETARY OF EDUCATION OF BELÉM: EXPERTISE IN LITERACY PROJECT IN THE "LOOK" TEACHERS}

\section{ABSTRACT}

The article aims to analyze the Expertise Project Literacy, which makes up one of the actions of continuing education policy of the Municipal Secretary of Education in Belém. More specifically, we analyze the relevance of this training project to the work of literacy teachers, perceiving the performance results of logic and the demands of

\footnotetext{
${ }^{1}$ Mestre em Educação na Linha de Políticas Públicas Educacionais. Possui graduação em Pedagogia pela UFPA e Pós graduação em Metodologia da Pesquisa Científica pela Universidade Estadual do Pará. E-mail:mary.josi@yahoo.com.br

${ }^{2}$ Doutora em Educação (Currículo) pela Pontifícia Universidade Católica de São Paulo (2000). Professora Associado III da Universidade Federal do Pará na graduação e na Programa de Pós Graduação em Educação-PPGED. Email: neycmo@ufpa.br
} 


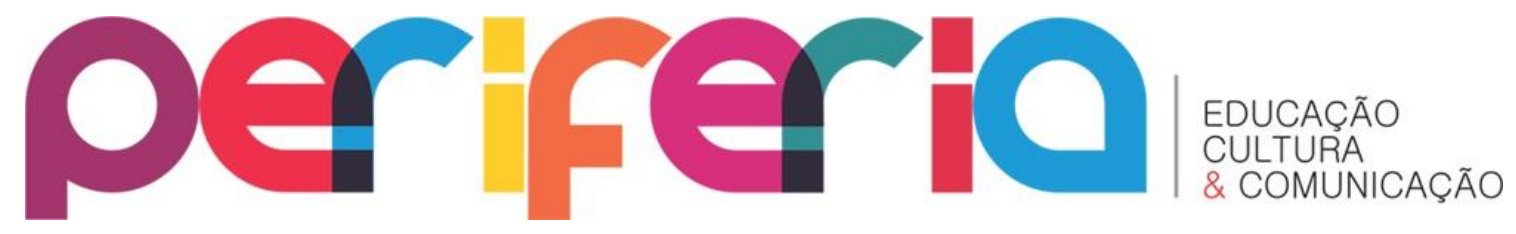

meeting targets. As a methodological base, we used the qualitative research approach, and as instruments of data collection semi-structured interview. The data were organized into categories and interpretative based on discourse analysis. We note, in the words of the teachers that the formation of Expertise Project has assigned responsibilities, in addition to working conditions provided by the education department.

Keywords: continuing education; teachers; literacy. 


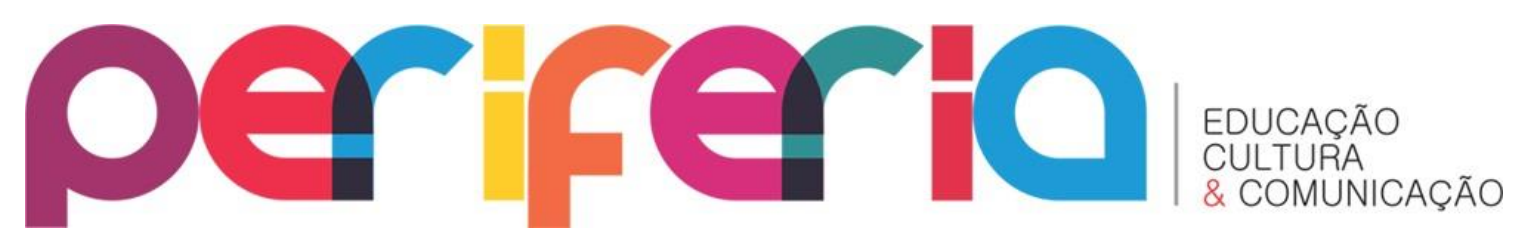

INTRODUÇÃO

A Secretaria municipal de educação de Belém- SEMEC desde 2007 vem desenvolvendo o Projeto de Formação Continuada, chamado "Expertise em Alfabetização" para os professores do ciclo inicial do ensino fundamental com objetivo de superar "o baixo rendimento do alunado, no tocante à leitura, à escrita e ao desenvolvimento do conhecimento lógico matemático" (BELÉM, 2006, p. 6).

O Projeto "Expertise em Alfabetização", é desenvolvido e acompanhado pelo Centro de Formação da SEMEC, que tem como principal objetivo realizar formação continuada aos professores alfabetizadores do primeiro ciclo (composto por 1 으, 2 을 e 3 응 anos), denominado Ciclo da Alfabetização e acompanhar estes professores na escola. O centro de Formação conta com uma equipe de funcionários efetivos que acompanham e realizam a formação no município.

Dessa forma, o artigo teve como objetivo analisar a proposta de formação continuada do Projeto Expertise e sua relevância para o trabalho dos professores alfabetizadores, além de identificar de que forma tem sido implementada a lógica de resultados de desempenho por meio do cumprimento de metas pelos professores.

Para subsidiar a pesquisa teve-se o aporte metodológico da abordagem qualitativa, uma vez que trabalha com o universo de significados, motivos e aspirações dos sujeitos. Assim, entrevistamos oito professores e escutá-los nos proporcionou, conhecer o sentido atribuído ao fenômeno da formação continuada para depois submetê-lo a uma análise de interpretação de suas falas.

\section{A POLÍTICA MUNICIPAL DE FORMAÇÃO CONTINUADA DOS PROFESSORES EM BELÉM}

A secretaria municipal de educação de Belém - SEMEC tem uma política de formação continuada elaborada pela própria secretaria e realiza formação aos professores, sob a tutela de programas de Formação Continuada, desde 1992. Todavia, no início dessa trajetória de formação, o que existiam eram cursos desarticulados e palestras sem um sequenciamento das propostas. 


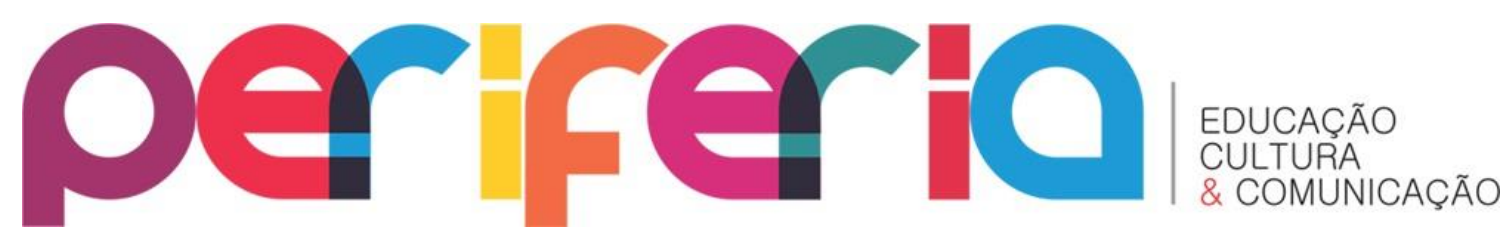

No período de 1993 a 1996, a proposta do governo tinha como eixo principal de sua gestão "a universalização qualitativa da educação básica em Belém", desenvolvido por meio de seis programas prioritários. Para assegurar essa universalização, destacouse um extenso programa de formação de professores com a criação do Instituto de Educadores de Belém (ISEBE). Esse órgão era responsável pela formação de professores, desenvolvendo Cursos de Fundamentação Teórica e Prática (ou Cursos de 360 horas), distribuídos em cinco etapas alternadas, compreendendo Fundamentação Teórica e Prática e Prática Assistida, destinadas a professores da Educação Infantil, do Ensino Fundamental e a técnicos (orientadores, supervisores e diretores administradores) (BELÉM, 1996).

No período de 1994-2004 a política de formação continuada em Belém consolidou um programa para além do modelo clássico, sob o nome de Projeto Escola Cabana, designando a formação centrada na escola incluída na jornada dos docentes, com a compreensão de processualidade nas ações a serem direcionadas. Esse projeto Escola Cabana teve como princípios centrais a participação popular e a inclusão social, orientando-se pelas seguintes diretrizes: acesso e permanência com sucesso, gestão democrática, qualidade social e valorização dos trabalhadores da educação (BELÉM, 1999).

A partir de 2005, Belém reorganizou a proposta de formação continuada com vistas a atender as exigências nacionais e locais. Nacionalmente, Belém estava abaixo dos índices da educação básica, segundo SAEB (2003) com a nota 3,0 na avaliação da qualidade do ensino da rede e, localmente, um quadro de alunos a serem alfabetizados com urgência, situação observada a partir de uma avaliação organizada pela SEMEC, para identificar os níveis de escrita, de leitura e de letramento em matemática das crianças do Ciclo I, constataram conforme análise de Cabral (2008) que $5 \%$ das crianças em idade escolar estavam fora da escola. Em contrapartida, 49,6 \% das crianças que frequentavam a escola apresentavam distorção na série e/ou idade, confirmando a situação das crianças com dificuldade de prosseguir os estudos. 


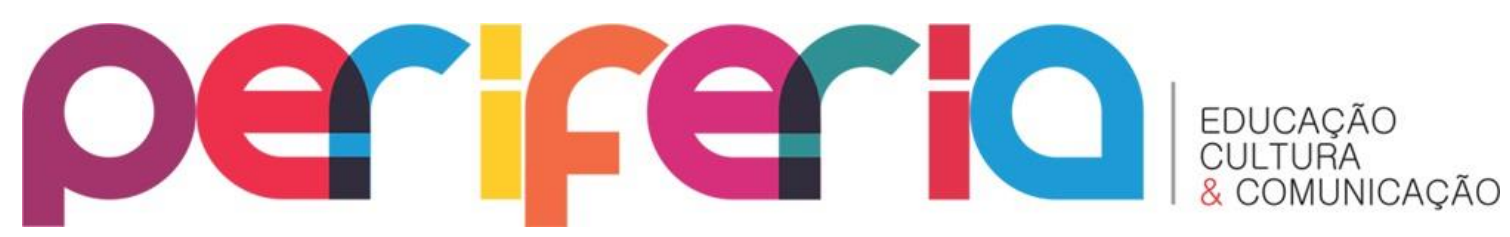

Para intervir nesse cenário desafiador, a Secretaria opta por assumir os resultados do SAEB (2003), que denunciavam a gravidade e a complexidade da educação ao informar à população a situação da aprendizagem dos alunos do Ensino Fundamental em leitura, em escrita e em matemática com dados alarmantes (BELÉM, 2005).

Esse contexto levou Belém, a criar o Centro de Formação de Professores em 2005, como um espaço para elaborar e formar os professores de forma contínua. Assim, implementou em 2005 o programa de formação continuada " elaborando conhecimento para aprender a reconstruir"- denominado ECOAR.

O seu objetivo era criar condições ao professor de estudar, de refletir e de reconstruir sua ação para a melhoria da aprendizagem do aluno, com o foco principal na ação pedagógica do professor e na aprendizagem do aluno das séries iniciais do Ensino Fundamental.

O ECOAR integra três grandes eixos de ação: 1) a expansão da Educação Infantil; 2) a formação continuada dos professores e 3) a educação ambiental para o desenvolvimento humano sustentável. Também, compreende três ações: 1) cursos semestrais sequenciais de seis dias, de segunda a sábado, das $8 \mathrm{~h}$ às $12 \mathrm{~h}$ e das $14 \mathrm{~h}$ às $18 \mathrm{~h}$, totalizando $48 \mathrm{~h}$ cada curso; 2 ) assessoramento às escolas, e 3) continuidades dos estudos na Hora Pedagógica do professor na escola onde trabalha.

A SEMEC desenvolve a formação continuada dos professores fundamentada no direito do professor estudar, entendendo que estudar não significa participar do evento. Significa substancialmente desconstruir e reconstruir sistematicamente a trajetória formativa e profissional, utilizando as metodologias mais atualizadas de aprendizagem: pesquisa, elaboração própria (BELÉM, 2005, p. 12). A metodologia do curso propõe a pesquisa e a elaboração própria, baseando-se em momentos de leitura e de reflexão, de discussão, de dramatização, de sessões de filmes, de trabalhos em equipes e da assembleia.

Ao longo das formações, a pesquisa era vista como uma espécie de princípio educativo, porque está fundamentada no saber pensar, no aprender a aprender e no 


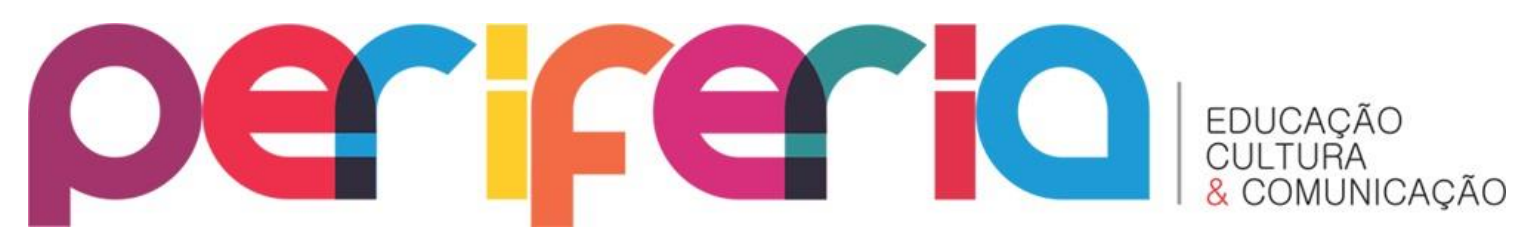

pensamento reconstrutivo, tendo em seu encalce os objetivos de proporcionar uma experiência concreta da realidade, orientar a investigação a partir de hipóteses previamente elaboradas, identificar no objeto de investigação os elementos relevantes para a explicitação do conhecimento em processo de (re) elaboração, exercitar o discernimento e a capacidade de elaboração a partir da realidade, verificar que há espaços alternativos e inesgotáveis de aprendizagem, no ambiente biofísico e social (BELÉM, 2005).

A equipe responsável por esse programa era chamada de Grupo Base, formado por professores efetivos da secretaria, pós-graduados com especialização e/ou mestrado. Profissionais com experiência em formação de professores (BELÉM, 2009) tendo como função assessorar, orientar, realizar as formações e de acompanhar os professores, após o curso Ecoar de seis dias.

Em suma, conforme documento do ECOAR (2009), foram realizados 34 cursos com a metodologia de seis dias durante os anos de 2005 a 2008. Após o curso de seis dias, a equipe reformulou a metodologia das formações e criou, em 2007, como uma dimensão do Programa ECOAR, o Projeto Expertise em Alfabetização, atrelado diretamente à formação de professores do ciclo de alfabetização (1으, 2ㅇ e 3ㅇano) e de coordenadores pedagógicos dentro do contexto da escola.

O Projeto Expertise em Alfabetização foi criado em 2007 para atender uma necessidade da SEMEC no que se refere aos baixos Índices de Desenvolvimento da Educação Básica (IDEB). Investir na formação dos professores alfabetizadores do ciclo I foi uma estratégia para superação desse resultado, por considerar que "uma requalificação da escola pública comprometida com a formação das crianças não pode prescindir da qualidade da escolarização ofertada, a começar por um efetivo letramento" (BELÉM, 2009, p. 2).

O Projeto Expertise em Alfabetização tem como objetivo formar professores capazes de alfabetizar os alunos em um ano, com a meta de alfabetizar $100 \%$ dos alunos. Para atingir os objetivos propostos, organiza-se de forma a envolver todos os 


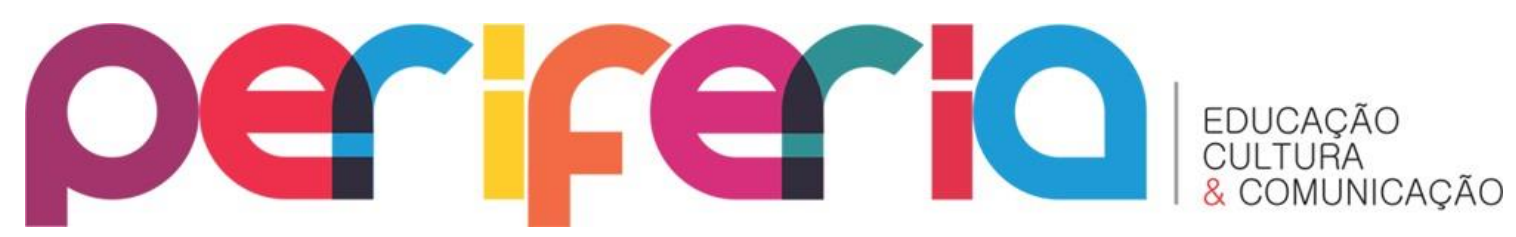

sujeitos do processo: formadores, coordenadores pedagógicos, professores, pais e alunos.

Metodologicamente, a equipe do Projeto Expertise realiza os encontros gerais e os encontros distritais, que são presididos pelas equipes formadoras, reúnem os professores por ciclos de atuação e o processo metodológico dá-se por meio de grupos pequenos de estudos a partir de temas definidos pela coordenadoria. Os formadores também planejam as pautas destas formações com base nas avaliações feitas durante o assessoramento às escolas acompanhadas e tem como pressuposto de formação a articulação do que é discutido ao contexto de trabalho. Para ser efetivado, tomam "o eixo da formação de professor e a reflexão sobre a prática como um dos caminhos da teorização, o que implica a realização de complexos dispositivos de formação" (BELÉM, 2009, p. 13).

O Projeto desenvolve o trabalho fundamentado em alguns eixos de ação, que são a "alfabetização das crianças em um ano, didática que leve à aprendizagem, avaliação mensal dos níveis de alfabetização, avaliação como suporte para a intervenção no processo de aprendizagem da leitura e da escrita" (BELÉM, 2009, p. 7). Prioriza, dentre as ações, um assessoramento sistemático do trabalho do professor com avaliação do trabalho do aluno mensalmente e a participação do professor nas formações mensais ocorridas nas escolas sede.

Kulchetscki (2013) avalia que as metas estabelecidas para Belém pelo INEP, em relação ao IDEB, demonstram alguns resultados ao comparar os dados obtidos no IDEB e as Metas Projetadas entre 2007 e 2011, observa que os resultados superam as metas estipuladas. Isso indica que, se for mantido o ritmo de crescimento, em 2021 irá ultrapassar a meta de 5.3, expectativa do IDEB, isso representa um grande avanço e atende aos objetivos da secretaria de educação com o programa de formação continuada.

Domingues (2013), também aponta aspectos relevantes da formação tais como a equipe de formadores ser composta por efetivos da própria secretaria, o incentivo pela produção individual ou coletiva como resgate aos saberes dos professores. 


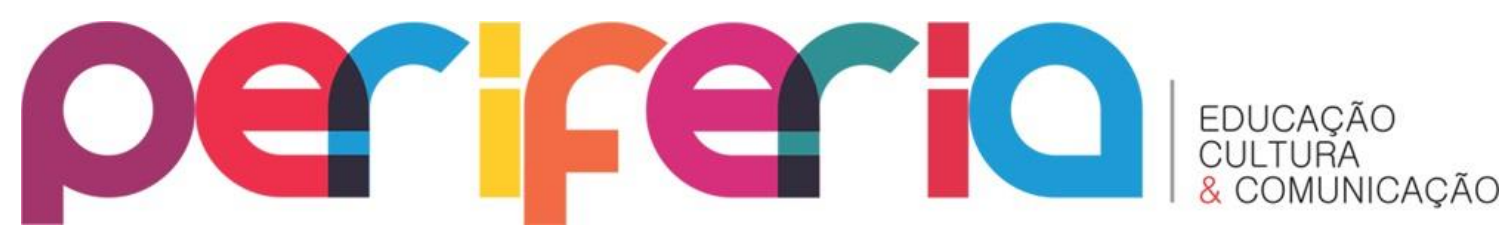

Kulchetscki (2013, p. 1) constata que "os professores avaliam positivamente a proposta desenvolvida pelo programa de formação, ao mesmo tempo que valorizam a oferta dos cursos e os consideram como espaço para troca de experiência e de valorização profissional".

Entretanto, os desafios e as críticas indicam "que as propostas elencadas para a melhoria do ensino não levam em consideração as implicações que as condições objetivas de trabalho têm para a prática docente" (KULCHETSCKI, 2013, p. 1), além do foco das formações serem quase que exclusivamente na dimensão cognitiva, não levando em consideração outros aspectos da vida do professor como o ético, o político, o cultural, o lúdico, que contribuiria para uma formação mais sólida (DOMINGUES, 2013).

Para Kulchetscki (2013), há duas questões instigantes que exigem reflexão ao se comparar o IDEB de 2007 a 2011 de Belém: até que ponto o aumento dos índices de uma escola é sinônimo de qualidade e que concepção se tem de formação do professor ao restringir o foco em alcançar os índices do IDEB? Confinar, pois, a qualidade da educação ao que se pode mensurar nas avaliações é restringi-la a uma atividade técnica, obliterando sua dimensão política.

\section{O PROJETO EXPERTISE EM ALFABETIZAÇÃO: ORGANIZAÇÃO, CONCEPÇÃO.}

O Projeto Expertise em Alfabetização ${ }^{3}$ é uma dimensão do Programa de Formação ECOAR, desenvolvido pela Secretaria Municipal de Educação, com mudanças nas estratégias de formação continuada dos professores, sendo reestruturado para ocorrer com atividades $\mathrm{o}$ ano inteiro aos professores alfabetizadores.

A alfabetização do Projeto Expertise, tem como base o ensino da leitura e da escrita para os alunos, por meio de diferentes gêneros textuais, estabelecendo uma dinâmica entre o aluno, o professor e as situações de ensino- aprendizagem (BELÉM, 2009), ou seja, alfabetização não é apenas ensinar o aluno a ler e escrever, mas

\footnotetext{
${ }^{3}$ Ver http://www.expertiseemalfabetizacao.blogspot.com, no qual o Projeto Expertise em Alfabetização compartilha informações das agendas da formação e o desenvolvimento e ações do Projeto.
} 


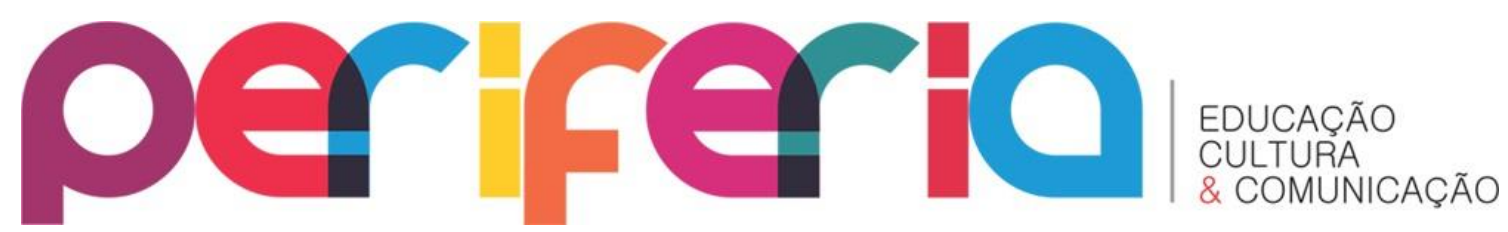

possibilitar a ele a compreensão do que lê e escreve, em uma perspectiva de letramento.

O Projeto agrega a concepção de letramento no conceito de alfabetização em uma perspectiva de que é necessário alfabetizar letrando, ou seja, ensinar a ler e escrever no contexto das práticas sociais da leitura e da escrita (BELÉM, 2009).

O documento do Projeto Expertise registra a sua pretensão de que os professores do 1 을 ciclo de alfabetização tornem-se um "expert" em alfabetização, contribuindo, assim, para alcance das metas do Plano Nacional de Educação e do Compromisso Todos pela Educação que é "alfabetizar as crianças até, no máximo, os oito anos de idade" (BELÉM, 2009, p. 7).

Para potencializar os objetivos do Projeto, promove formação também aos coordenadores pedagógicos das escolas com a finalidade de focar o elemento desencadeador do processo de alfabetização para as turmas do ciclo. Os idealizadores do projeto acreditam que as crianças na faixa etária de 7 a 8 anos podem produzir textos escritos, seguindo os critérios da avaliação textual.

A formação do Expertise tem a intenção de que os professores sejam capazes de alfabetizar os alunos até o final do ano, estabelecendo metas a serem atingidas para alcançar $100 \%$ de crianças alfabetizadas com 6 anos de idade no 10 ano. Essa tendência que vem direcionando a formação continuada com base em alcance de metas, sendo próprio das exigências atuais, tem atribuído à educação um caráter pragmático, reduzindo a ação do professor em muitos casos à preparação para resolução de problemas.

O estabelecimento de metas pela secretaria possibilita segundo o projeto Expertise em Alfabetização, acompanhar de forma mais sistematizada se os professores estão alfabetizando ou não dentro do tempo estipulado. Entretanto, não acreditamos que esse acompanhamento, a partir de determinações apriorísticas sobre as metas, que não são construídas coletivamente, venha ajudar de forma mais contundente os professores, uma vez que os alunos possuem ritmos de aprendizagem 


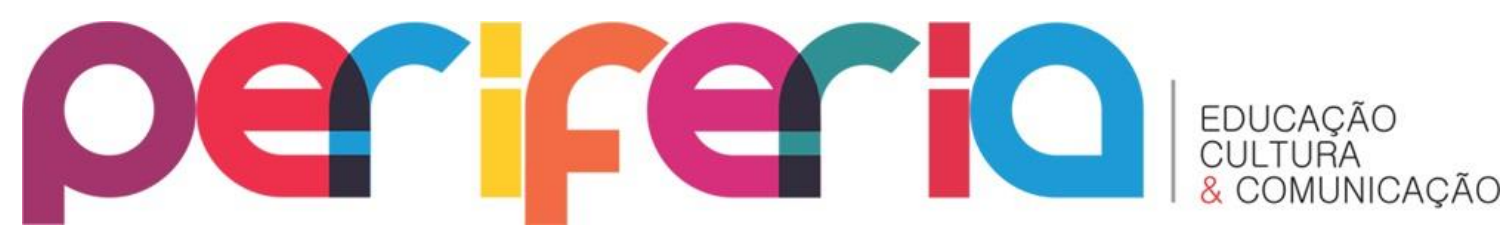

diferentes, além de que outros fatores, que perpassam pelas condições de trabalho destes professores até ao cumprimento das metas, precisam ser discutidas.

Desde 2009, o Projeto Expertise atende todas as escolas da rede municipal de educação de Belém que oferecem o ciclo de alfabetização. Os dados informados pelo Centro de Formação (2014) contabilizam 64 escolas e 52 unidades pedagógicas com um total de 700 professores e 19.500 alunos, acompanhados pedagogicamente.

O Projeto, ao enfocar as escolas como locus de formação, visa como estratégia consolidar as condições didáticas necessárias para a alfabetização das crianças. Os professores, segundo as diretrizes do Projeto, deverão ser "levados a acreditar na capacidade do aluno de ler, escrever, para conseguirem, assim, alcançar a meta de $100 \%$ dos alunos alfabetizados" (BELÉM, 2009, p. 9), posto que as estratégias previstas e as atividades sugeridas encaminham-se para a iniciativa e para a autonomia do professor, cujo formador é referência de orientação e de avaliação.

A formação acontece uma vez ao mês nas escolas sede no dia da Hora Pedagógica do professor ou no Centro de Formação, ou nas escolas sede por distritos, seguindo uma agenda previamente definida e divulgada no blog do Expertise em Alfabetização sob a responsabilidade de uma equipe formadora.

A equipe formadora tem a responsabilidade de elaborar o contrato didático com os professores, de orientar o planejamento para a aula, assim como também se responsabilizar pela orientação e pela análise da regência de classe, pois, caso seja preciso, os formadores acompanham os professores em atuação, porque, observando as dificuldades, poderá sugerir intervenções, orientação de avaliação, análise do instrumento de avaliação e do resultado, estudo na HP, reunião com coordenador e reunião com os professores (BELÉM, 2009).

O Grupo Base planeja a pauta da formação coletivamente entre os formadores, com a justificativa de garantir uma unidade ao responder às "contribuições dos formadores, advindas dos estudos teóricos sobre alfabetização em confronto com a análise dos resultados da avaliação das crianças e da prática dos professores" (BELÉM, 2009, p. 10). 


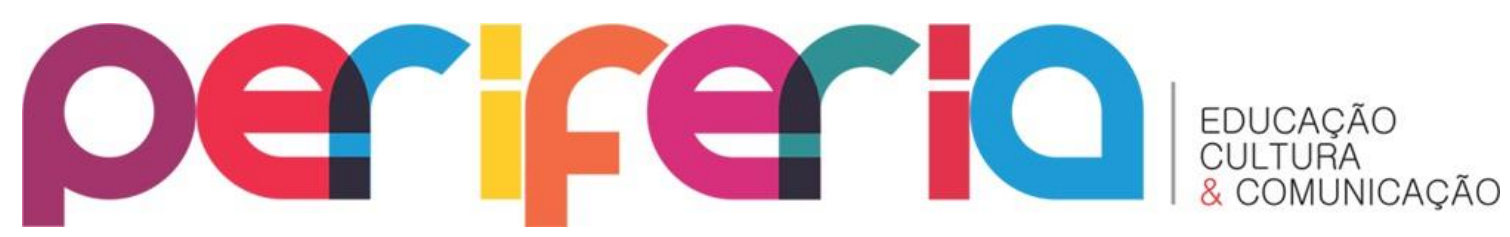

Cada momento de formação tem uma carga horária de quatro horas (mensal) com o acompanhamento dos formadores nas escolas sede, quatro horas (quinzenais para estudo) para a produção de material didático e planejamento de sequências didáticas, restando quatro horas (mensal) para sistematização e análise dos resultados da avaliação das crianças pelos professores nas escolas.

Durante as quatro horas/mensais, os professores se reúnem, em média vinte (20) por grupo de formação, para estudo coletivo, para planejamento, para troca de experiência do trabalho de sala de aula. As pautas dos encontros, geralmente, são: acolhida (texto/dinâmica, auxílio ao professor para fazer em sala de aula), frequência (quadro de frequência padronizado em forma de estrela correspondendo o dia do mês da formação para os professores pintarem de verde se presente, vermelho se ausente, laranja se ausente com justificativa).

Agregam-se ao encontro o texto a ser estudado (leitura coletiva com debates), trabalho em equipe (inclui planejamento das sequências didáticas, trocas de experiências exitosas), socialização desse planejamento e compartilhamento da situação das turmas (tabela com gráfico por turma de cada professor e os níveis da psicogênese de cada aluno). Por último, após o relato de experiência ou demonstração de recurso que deu certo na turma, são escolhidos, em média, dois professores para socializar por formação.

Em relação a essa organização da formação mensal, sempre é enfatizado a qualificação do tempo de aula dos professores. Assim, entre os momentos discutidos na formação, a sequência didática sempre é prioridade para que a formadora avalie como foi realizada a distribuição do tempo pelos professores.

Outro aspecto a ressaltarmos é que nos compêndios entregues aos professores já vem planejado as sequencias didáticas em alguns momentos, os professores se reúnem para avaliar e complementar algumas atividades que considerem relevantes.

A sequência didática apresentada é construída seguindo algumas orientações as quais são: aproveitamento do tempo de aula e dia letivo para cuidar da aprendizagem; ensinar o aluno a escrever seu próprio nome; propor atividades 


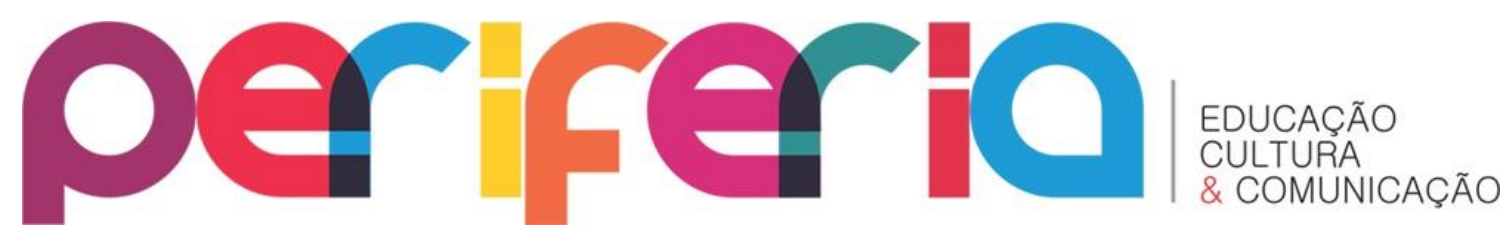

didáticas que levem o aluno a pensar sobre a escrita; ler bons textos para as crianças e trabalhar com atividades de escritas todos os dias; realizar atividades diversificadas com letras, palavras, frases e textos, explorando diferentes campos semânticos; propor jogos didáticos com letras, números; explorar o livro didático; e propor todos os dias tarefas para os alunos realizarem em casa.

A sequência didática, por sua vez, deve avaliar o nível de conceitualização da escrita com ideias da psicogênese, mensalmente, analisando e comparando resultados, com interesse de orientar o planejamento. Todas as escolas seguem esse paradigma de planejamento semanal das aulas, o que the sugere um caráter homogêneo. Apesar da possibilidade de adaptação pelos professores acerca da sequência trabalhada, em virtude da dimensão do que precisam dar conta entre uma formação e outra, essas sequências são trabalhadas com poucas modificações diante daquelas sugeridas pelo grupo na formação.

Ao término dos encontros de formação, cada professor entrega ao formador uma pasta com as avaliações mensais feitas pelos seus alunos e tabuladas por quantidades de acertos e erros de cada aluno em uma planilha. Esta última permite ao formador acompanhar a trajetória de desenvolvimento cognitivo da turma. Concomitante a essa entrega, o professor recebe uma nova avaliação, uma matriz para fazer com a sua turma para o mês posterior.

Como o Projeto Expertise visa dentre outras questões à aprendizagem dos alunos em português e em matemática, desenvolve um processo avaliativo para acompanhar mensalmente o desempenho dos alunos, baseado nas escritas deles, no acompanhamento sistemático da prática docente em sala e no registro reflexivo, por escrito, do percurso de aprendizagem dos sujeitos envolvidos.

Na direção da discussão da avaliação por resultados, com o propósito de averiguar se, de fato, a meta de alfabetizar $100 \%$ está sendo encaminhada, os formadores organizam mensalmente uma prova de português e de matemática e entregam-nas aos professores para que os mesmos aplicarem em sala de aula. Essa 


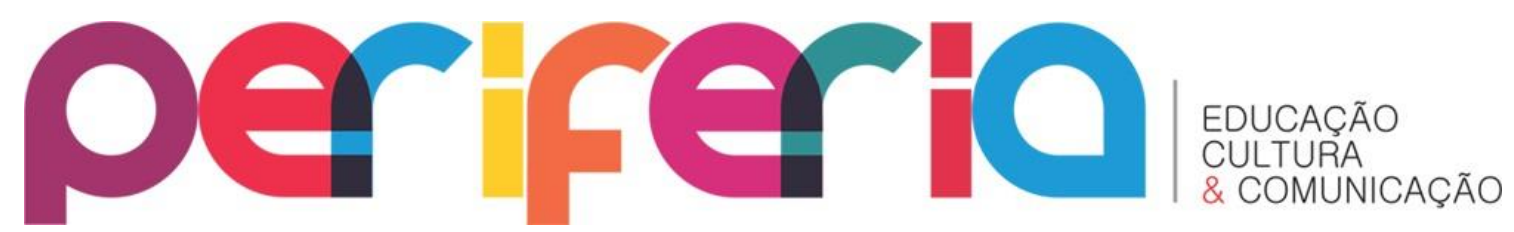

prova serve como orientação à equipe formadora do percurso do trabalho e ao mesmo tempo de controle.

Assim, o professor aplica uma prova de português e de matemática elaborada pela equipe formadora do Centro de Formação aos alunos mensalmente. Logo em seguida, fazem uma análise da produção de leitura, de escrita e de matemática e são feitas com base em critérios avaliativos e com atribuição de pontos que variam de 0 a 2. Conforme a pontuação, em português, a escrita do aluno é colocada em um nível que vai do nível pré-silábico, silábico, silábico-alfabético nível alfabético, e, na prova de matemática, os alunos são avaliados e enquadrados no nível pré-numérico, numérico I, numérico II ou numérico III.

Durante as avaliações os professores deverão realizar o ditado, sendo que as palavras a serem ditadas pelo professor são quase sempre sugeridas pelo formador, bem como a história a ser lida. Após esse momento, ele faz a correção e vai pontuando a prova do aluno seguindo os critérios avaliativos definidos pelo grupo de formação; cada item recebe uma pontuação. Essa avaliação não substitui a que o professor faz com o seu aluno. É uma prova a mais para mapeamento do desenvolvimento cognitivo do aluno no que se refere à escrita e à leitura.

Depois que os professores fizerem as duas avaliações com os alunos e a tabulação dos níveis de cada criança (tanto da escrita e da leitura quanto do conhecimento numérico) por turma, eles sintetizam os resultados em uma planilha e entregam-na, junto com as provas aplicadas, à formadora, que fará o processo de comparação. Se o que o professor tabulou confere com as provas que os alunos responderam, o formador faz uma síntese com a utilização de um programa de computador específico, tabula os dados e os transforma em gráficos, que resultam em uma planilha síntese, fornecendo o desempenho individual por turma e alunos (mês e ano).

Com essa organização pedagógica do Projeto, a secretaria anuncia alguns resultados registrados que "a maioria das crianças do $\mathrm{Cl}$ 10 ano (06 anos) escreve seu 


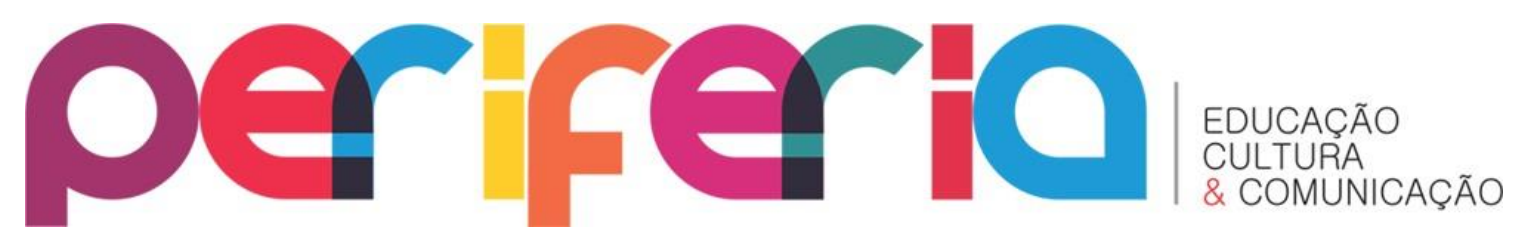

próprio nome; o acompanhamento do processo de aprendizagem indica avanços na alfabetização dos alunos em escrita e matemática" (BELÉM, 2009, p. 7).

Essa dinâmica da formação continuada nos conduz a afirmar que os fundamentos epistemológicos do fazer do professor e do porquê fazer ficam esvaziados apenas, como nos diz Veiga (2012), no micro universo da sala de aula, reduzindo a educação à resolução de problemas contextualizados. A função do professor fica restrita a ministrar aulas eficientes, otimizando o seu tempo em sala de aula, tornando-se, com isso, um reprodutor de métodos e de técnicas produzidos por outros.

O entendimento da formação como um processo que a pessoa, em formação, realiza sobre si mesma e o conhecimento, como instrumento para resolução de problemas práticos imediatos, visa à elaboração de ações adequadas aos contextos e às próprias possibilidades neles existentes. Significa, em última instância, preparar os indivíduos para a plena adaptação às circunstâncias, sem debruçar-se sobre a real compreensão de seus determinantes. Então, em que perspectiva nós, como professores, estamos analisando esse momento? Como os professores que fazem parte do Projeto Expertise veem a formação continuada? Afinal, o que eles dizem sobre o Projeto que participam?

\section{O QUE FALAM OS PROFESSORES ENTRE O DITO E O NÃO DITO E O QUASE DITO DA FORMAÇÃO DO PROJETO EXPERTISE}

Na fala dos professores sobre a formação continuada do Projeto Expertise manifestam-se as ideias de uma formação como espaço de repasse de metodologias, subsídios para desenvolver atividades, uma ajuda para a prática em sala de aula e estratégias de como o professor deverá trabalhar. Em síntese, uma demonstração clara de como se deve ensinar nas escolas, ressoa como um direcionamento da formação basicamente prática, restrita ao saber fazer. 


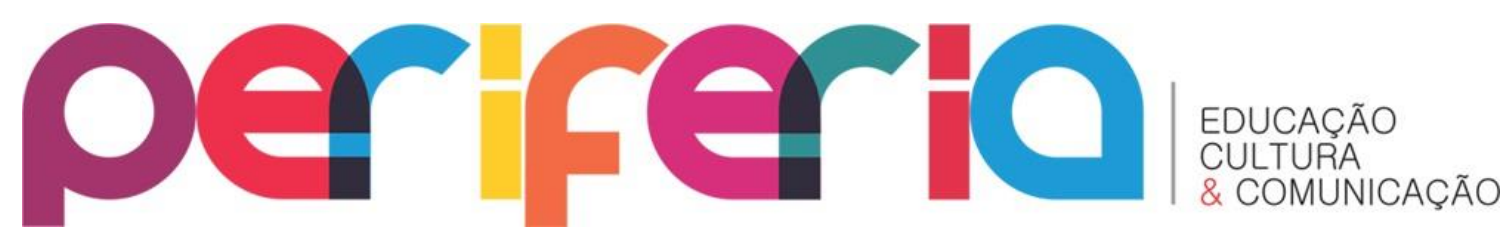

A formação continuada segue aproximações de uma formação prática quando as suas preocupações ligam-se ao repasse de estratégias de como trabalhar em sala de aula, conforme é atentado nas vozes dos professores,

PROFESSOR 01: Na minha visão, o projeto Expertise tem o objetivo de formar, buscando novas metodologias, novas experiências para que a gente possa se formar e aplicar essas atividades de forma diferenciada e diversas na sala de aula haja vista que o objetivo deles seja $100 \%$ alfabetizados na idade certa. Então, a formação do Expertise é buscar alternativas[...]novos roteiros de atividades que se use na sala de aula, tem que adaptar a sala de aula.

Essa fala, expressa e sintetiza o que dizem os professores, que a formação continuada do Expertise possui uma função de instrumentalizá-los em seu fazer pedagógico, com "dicas" de como agir, levando novas técnicas de ensino, novos roteiros de atividades centradas no ensino de atividades para serem desenvolvidas em sala de aula, sendo que consideram como uma necessidade dos professores.

Eles dizem que a formação deve existir sempre, porque auxiliam na sua prática, uma vez que "você vai obter novos conhecimentos, novas técnicas, você vai aprender novas metodologias, enfim, você vai ter um novo olhar de sua didática de ensino [...]" (PROFESSOR 01). Isso nos leva à constatação de que há o anseio por uma formação na qual seja disponibilizada aos professores "novos roteiros de atividades".

Os professores valorizam muito o projeto de formação que primam por oficinas que tragam ideias de como fazer na sala de aula. É o que constatam também pesquisas de Gatti, Barreto e André (2011). Entretanto, as vozes dos professores entrevistados revelaram a disputa de concepção de formação em que, ao mesmo tempo que se questiona uma reflexão mais crítica de sua realidade, uma formação com uma base teórica mais sólida, também se conclama a uma formação eminentemente prática, pois, segundo os professores, possibilita-os aprenderem mais e dar menos trabalho.

A articulação da teoria com a prática na formação continuada é indispensável, indissociável, segundo Gatti (2012, p. 97), que alerta para que haja uma relação 


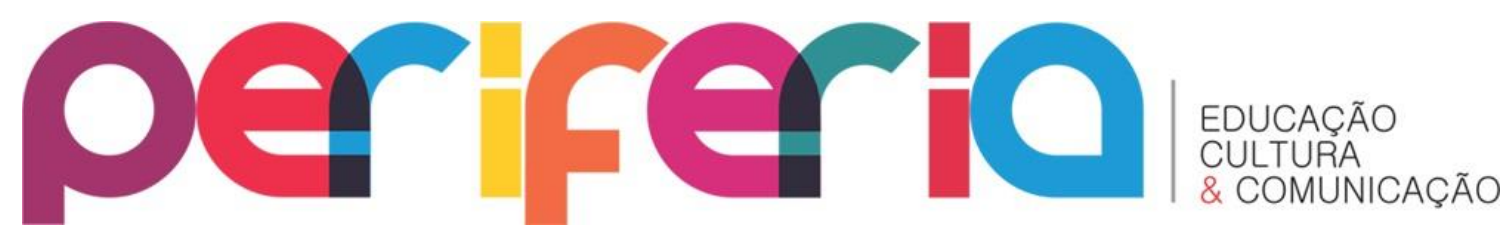

dialética nas práticas educacionais que "têm seus fundamentos teóricos e associam-se a uma filosofia educacional. Práticas geram teorizações e teorizações geram práticas".

Todavia, a formação tem dado base para um um monitoramento do trabalho pedagógico desse professor, uma vez que direcionando a pauta da formação, que deverá ser executada dentro de um prazo estipulado durante as formações continuadas. A pauta do encontro gira em torno dos textos a serem utilizados, da ambientação alfabetizadora da sala, dos cartazes que devem ser fixados, das sequências didáticas e das avaliações que devem ser efetivadas.

Tudo isto demonstra um controle do trabalho do professor e de algumas questões que antes eram de competência deles, tais como o planejamento de ensino e as avaliações internas, as quais, desde a implantação do projeto, chegam préelaboradas pela secretaria, cabendo ao educador somente aplicá-las e completá-las, caso julgue necessário. Na verdade, não passa de um monitoramento do conhecimento de forma centralizada em relação ao fazer pedagógico. A fala abaixo confirma essa constatação e anunciam mudanças nas didáticas pedagógicas dos professores:

PROFESSOR 04: [...] eles não aceitam se a gente coloca um painel de sílabas na parede, porque como ela disse se hoje você trabalha o texto da Estela conta estrela, o "es" vai ter uma dificuldade com essa família, não vai aparecer no painel, isso é dificuldade, então eu prefiro trabalhar por parte, pego cinco palavras trabalho as famílias, e peço para eles formarem outras palavras[...].

Considerando a fala do professor, podemos identificar que o dito é o desconhecimento da proposta de formação. Não há uma participação direta com base no que interessa aos professores para ser discutido na formação, também observamos que há uma exigência para colocar em prática o que está sendo repassado.

Os professores não questionam a não participação. Contudo, apontam que o projeto atende, em parte, as suas expectativas, ressaltando que as atividades repassadas durante a formação, às vezes, não são feitas do modo como é direcionado 


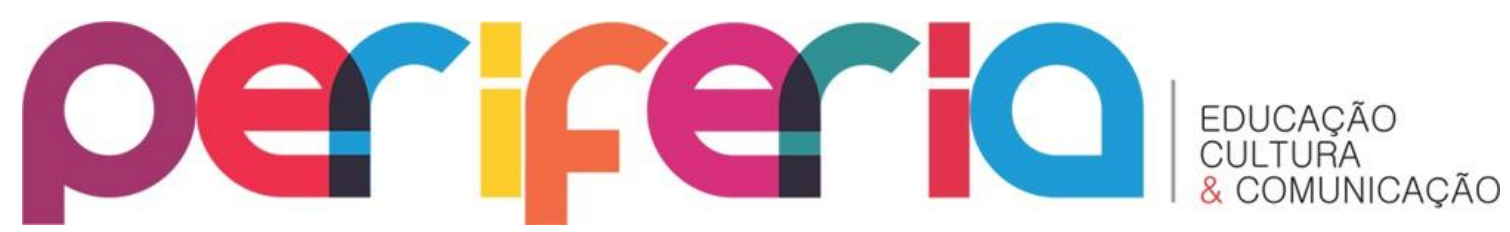

pelo grupo de formação, porque precisam adaptar, constatamos que a maioria do grupo entrevistado prefere adaptar atividades quase prontas do que criar.

Constatamos que muito embora valorizem o saber fazer em detrimento do saber pensar, eles têm uma pequena margem de autonomia que exercem ao não obedecer fielmente às regras estabelecidas pela secretaria. Para Lima (2011), isso são margens definidas como infidelidade normativa, que se explica quando as atividades escolares são reguladas por um campo normativo.

A princípio, o campo normativo é submetido à organização do trabalho, porém, entre a imposição das normas e a sua total aceitação em um extremo, faz com que se torne ajustável equilibrar em que medida as orientações da secretaria (externa) são, de fato, reproduzidas na escola. Desse modo, a produção de normas na escola não ocorre "naturalmente" pela razão de existirem diferentes possibilidades de os sujeitos interagirem com as regras externas. Assim, observamos nos discursos a posição de não aceitação de tudo da forma que vem:

PROFESSOR 07: [...] a gente faz o planejamento não necessariamente como vem na proposta (sequência didática) [...].

Os professores anunciam que o Projeto Expertise possui metas que são claras e objetivas, e que são, logo no início das formações continuadas a cada ano, apresentadas para que todos os envolvidos na formação tomem conhecimento. Para assegurar um compromisso com a formação, fazem um contrato didático e neste contrato a meta é explicitada: "Eles querem 100\% alfabetizados até junho" (PROFESSOR 05). Não sendo isso possível, o prazo é prorrogado até dezembro.

Os professores veem o estabelecimento de metas para o ensino como uma forma de ajuda e de incentivo para desenvolver suas atividades, por acharem que se não tiver meta, não se faz nada. A inclusão das metas acaba emplacando em um componente considerável para o sucesso do ensino segundo os professores. 


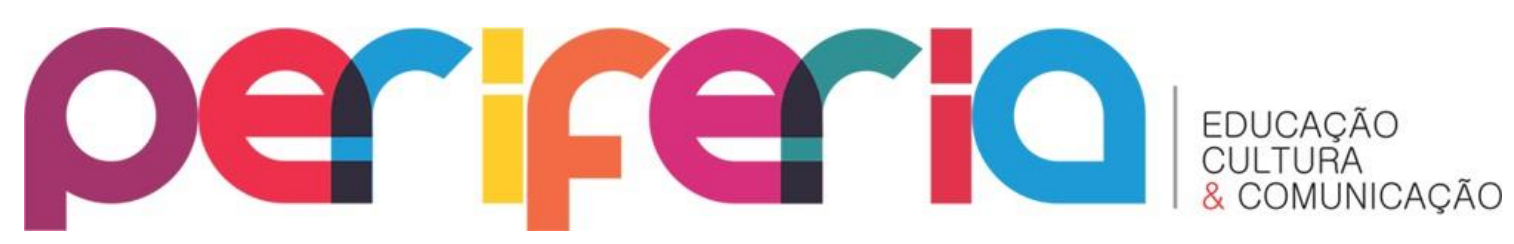

PROFESSOR 07: [...] todo grupo trabalha com metas, um projeto de formação como esse quando é elaborado, ele vem lá todo cheio das metas [...].

As metas possibilitam um controle do trabalho desenvolvido em sala de aula e esse controle se dá por meio de avaliações mensais feitas com os alunos, sob a orientação do professor da turma, o qual precisa prestar conta dos resultados de seu trabalho, se esse trabalho está dando certo ou não, se está cumprindo as metas ou não, havendo, para isso, uma planilha de acompanhamento mensal dos alunos por professor, que informa a situação da turma.

Sordi e Freitas (2013, p. 88) esclarecem que é preciso ter um acompanhamento do trabalho pedagógico do professor, ao estabelecer que a escola reivindique uma dinâmica da confiança relacional "baseada numa combinação de respeito, competência, consideração para com os outros e integridade. Uma deficiência em um desses critérios compromete a relação toda".

Pelas falas dos professores, percebemos uma relação de cima para baixo, as definições do que fazer e os executores do fazer na escola. Alguns deles se colocam em uma posição de aceitação das definições, chegando a sentirem-se bem por existir alguém que os está pressionando a terem resultados. Essa sensação faz "trabalhar mais e melhor", "te disciplina", uma vez que haverá alguém para quem prestar contas do seu trabalho e, com isso, não irá "relaxar" em seu compromisso.

Essas formações discursivas, construídas dentro da conjuntura do que os professores devem ou não dizer, dependendo de sua condição de produção, revelamnos que, primeiramente, a concordância ao cumprimento de metas apareceu como uma realidade favorável ao desenvolvimento do trabalho dos professores. Há a ideia de que as metas direcionam e os ajudam a chegar ao alvo, que é a aprendizagem dos alunos.

Logo em seguida, posicionaram-se como sendo impossível atingir essa meta de $100 \%$ dos alunos alfabetizados, dentro do tempo e prazo estipulados, uma vez que apontam outros fatores que intervém nesse processo, tais como: problemas sociais, 


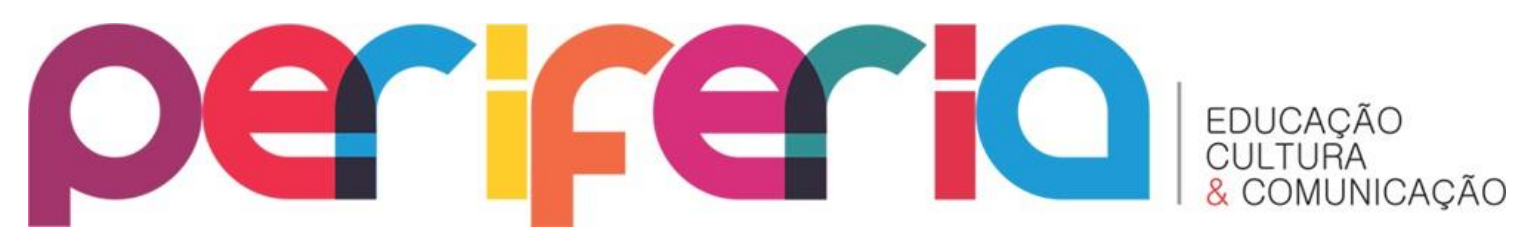

tráfico de drogas, problemas emocionais dos alunos, entre uma infinidade de problemática ligada a questões sociais e econômicas.

Outro aspecto que enfatizamos é que esse discurso fortalece a política de responsabilização de professores, por colocá-los como principais protagonistas desse processo, sendo convocados a apresentarem desempenho cada vez mais eficaz e eficiente. Verificamos, ainda, uma preocupação dos professores em tentar atingir essa meta quando pontuam que se sentem cobrados.

Testemunhamos certo "rankeamento" entre os professores pela busca de melhores resultados, consequência da lógica gerencial que norteia a política de formação em Belém, a qual prioriza a gestão por resultados, que se orienta por critérios de eficiência, de eficácia e de avaliação de desempenho. Sobre essa relação entre o cumprimento de metas e o desempenho dos professores, Santos (2004) examina que as políticas educacionais atualmente têm influenciado na criação de uma "cultura do desempenho" ou "cultura da performatividade" em que a performance dos professores se torna o ponto central desse processo.

PROFESSROR 01: Na minha turma, tenho 25 alunos, sendo 22 alunos já alfabetizados e 02 silábico-alfabéticos e 01 silábico e nenhum présilábico. Jogando para o gráfico, não vou ficar ruim diante dos outros.

Os sentidos dessas formações discursivas que analisamos da formação continuada é que essas questões que interferem na aprendizagem dos alunos, como as sociais, ressaltadas nas falas, não são privilegiadas no momento da formação. Não é difícil atentar-se para a angústia e o sentimento de medo de não alcançar metas, medo de ser considerado incompetente com receio de ser punido, medo de ser culpado, responsabilizado por parte dos demais professores. Esses são aspectos que não foram ditos, mas perpassam por suas vozes 


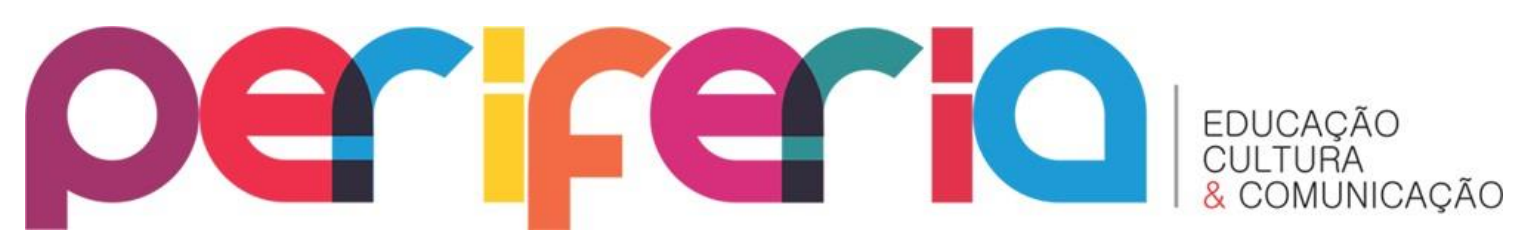

\section{CONSIDERAÇÃO FINAL}

Observamos na formação continuada do Projeto expertise em Alfabetização com acuidade, o enfoque a compreensão do professor como um prático, ou melhor, no próprio esvaziamento teórico, reduzindo-se a capacidade de ensinar dos professores à resolução de problemas e na utilização de novas técnicas de ensino, um reducionismo do fazer pedagógico que se caracteriza pela racionalidade técnica, centrada no micro universo da sala de aula.

De um modo geral, emerge das falas analisadas o controle do trabalho do professor pelo direcionamento do seu fazer pedagógico, no cerceamento de sua autonomia diante de suas funções referente à elaboração do planejamento, da organização de suas salas e da capacidade de avaliar o processo de ensinoaprendizagem dos alunos. Registramos ainda a não participação dos professores no processo de construção da pauta da formação, os quais se manifestam afirmando que não cumprem na íntegra com o que lhes são solicitados, sempre procuram uma forma de adaptar as atividades à realidade dos seus alunos.

Observamos também, a configuração do projeto direcionado e focado na aprendizagem de português e de matemática, e do professor responsável pela alfabetização com base em metas. A formação de um professor executor de atividades já pensada, organizada apenas para ajustar e para efetivar em sala de aula, tira a possibilidade de o professor analisar criticamente o fazer pedagógico, e até sem perceber ele fica condicionado ao que fazer na sua vida profissional cotidiana.

A formação continuada do Projeto Expertise em Alfabetização se constitui como suporte ao trabalho dos professores. Muitos, com certeza, veem com bons olhos a proposta, sem deixar, é claro, de estabelecer críticas para melhoria e mudança de perspectiva teórica e epistemológica dessa formação. Cremos que as mudanças em educação nunca devem vir somente revestidas pela crítica, mas devem, sim, em qualquer circunstância, se fazerem presentes como uma contraproposta acrescida a ela. 


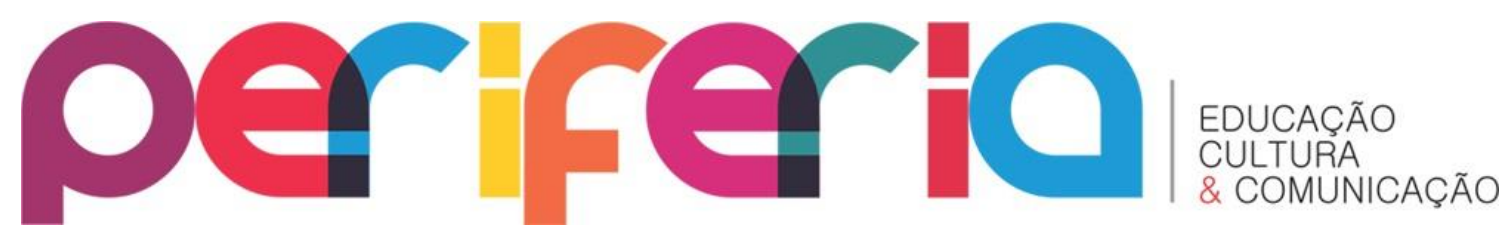

\section{REFERÊNCIAS}

BELÉM. Secretaria Municipal de Educação. Caminhos da Educação (Série Planejamento, n. 3). Belém: PMB/SEMEC, 1996.

Secretaria Municipal de Educação. Cadernos de Educação no 1. Escola Cabana: construindo uma educação democrática e popular. Belém, 1999.

Lei 8.655, de 30 de julho de 2008. Dispõe sobre o Plano Diretor do Município de Belém, e dá outras providências. Belém: Câmara Municipal de Belém, 2008, 122 p.

Secretaria Municipal de Educação. Programa de Formação Continuada de Professores. (Elaborando conhecimento para aprender a reconstruí-lo - ECOAR, 1은 curso semestral). Belém: PMB/SEMEC, 2005.

Secretaria Municipal de Educação. Programa de Formação Continuada de Professores. (Elaborando conhecimento para aprender a reconstruí-lo - ECOAR, 2ㅇ curso semestral). Belém: PMB/SEMEC, 2006.

Secretaria Municipal de Educação. Programa de Formação Continuada de Professores: Expertise em leitura e produção de textos. Belém: SEMEC/ECOAR, 2009.

CABRAL, M. do S. M. Programa de Formação de Professores continuada de professores dos Ciclos iniciais da Rede Municipal de Belém: a experiência formativa da pesquisa e elaboração própria (2005/2007). 2008. 137 f. Dissertação (Mestrado em Educação) — Universidade do Estado do Pará, Belém, 2008.

GATTI, B. A. Formação de professores e profissionalização: contribuições dos estudos publicados na Rbep entre 1998 e 2011. Revista Brasileira de Estudos Pedagógicos, Brasília, v. 93, n. 234, [número especial], p. 423-442, maio / ago. 2012.

GATTI, B. A; BARRETO, E. S. de Sá; ANDRÉ, M. Eliza D. de A. Políticas docentes no Brasil: um estado da arte. Brasília: UNESCO, 2011. 300 p.

KULCHETSCKI, D. M. Ecoar, um programa de formação continuada de professores: aproximações e distanciamentos. In: XI Congresso Nacional de Educação, Curitiba, 2013. Anais do XI Congresso Nacional de Educação - EDUCERE. Curitiba: PUCPR, 2013. p. 15796-15796.

LIMA, L. C. V. da S. Administração Escolar: estudos. Portugal: Porto, 2011.

SANTOS, L. de C. P. Formação de professores na cultura do desempenho. Educação \& Sociedade, Campinas, v. 25, n. 89, p. 1147-1157, set. / dez. 2004. 


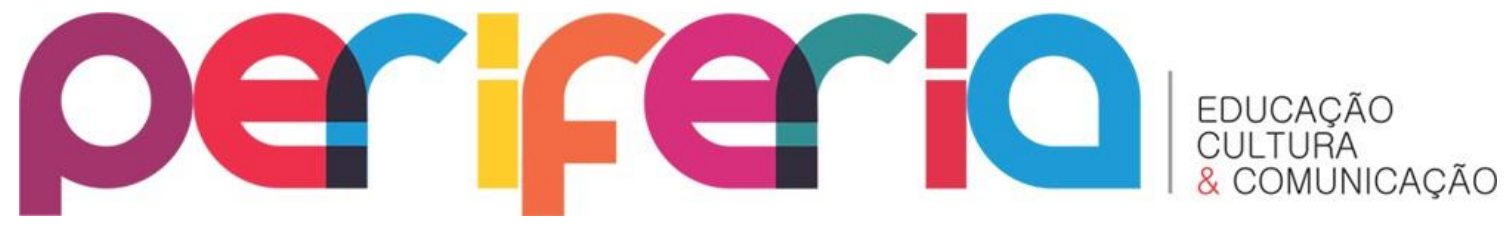

SORDI, M. R. L. de; FREITAS, L.C. de. Responsabilização participativa. Revista Retratos da Escola, Brasília, v. 7, n. 12, p. 87-99, jan. / jun. 2013. Disponível em:<http//www.esforce.org.br>. Acesso em: 10 maio 2014 